\title{
Detection of the contact tube to working distance in wire and arc additive manufacturing
}

\author{
Lennart Vincent Hölscher ${ }^{1}\left[\right.$ [ $\cdot$ Thomas Hassel $^{1} \cdot$ Hans Jürgen Maier ${ }^{1}$
}

Received: 12 November 2021 / Accepted: 22 January 2022 / Published online: 9 February 2022

(c) The Author(s) 2022

\begin{abstract}
Currently, wire and arc additive manufacturing (WAAM) is mainly done by planning the torch movements layer wise. The height step between the layers is derived from preliminary experiments. Small deviation in the determination of the height step can accumulate over the layers and lead to improper shielding gas conditions or a collision the between torch and the work piece. This makes continuous process monitoring necessary. To overcome these problems, a closed-loop layer height control strategy is beneficial. For the development of a closed-loop height control strategy, it is necessary to have knowledge of the effective height step between the layers during manufacturing. The present study focuses on the development of a sensing method, which allows users to detect the contact tube to working distance (CTWD) in WAAM. The system was developed for short circuit mode of gas-metal arc welding WAAM. The system can also provide information on whether the torch passes over weld beads crossing the weld track or other geometric irregularities existing in the $z$-direction. Several characteristic values of the process were detected and were matched to the actual CTWD. The accuracy of the sensing method was evaluated, and based on the measured correlation and standard deviation, the electrical resistance during short circuit monitored the CTWD best.
\end{abstract}

Keywords Contact tube to working distance - Gas-metal arc welding · Wire and arc additive manufacturing · Height step · Layer-wise manufacturing

\section{Introduction}

Wire and arc additive manufacturing (WAAM) allows the build of fully dense metallic components by using the welding arc to melt material onto a work piece in a layer-wise fashion [1]. Additive manufacturing can lead to huge savings in material costs, when work pieces with high buyto-fly ratios are build [1]. WAAM can also be used to produce functional graded materials [2] or to strengthen work pieces during manufacturing [3]. Two different arc welding

Lennart Vincent Hölscher

hoelscher@iw.uni-hannover.de

Thomas Hassel

hassel@iw.uni-hannover.de

Hans Jürgen Maier

maier@iw.uni-hannover.de

1 Institut Für Werkstoffkunde (Materials Science), Leibniz Universität Hannover, An der Universität 2, 30823 Garbsen, Germany techniques are used for WAAM, gas-tungsten arc welding (GTAW) and gas-metal arc welding (GMAW) [4-6].

Currently, WAAM is done by using a software, which divides the work piece into slices with the same predefined height. The layer height is estimated based on previous experiments. The determination of the correct parameters involves many preliminary parameter studies on similar shaped parts [7], as every material, wire diameter, and shielding gas combination leads to different results. Furthermore, the weld beads are influenced by many additional parameters such as trajectory, angle of inclination, and interlayer temperature. Since different geometries lead to different heat fluxes, the height-step prediction is only valid for similar geometries [7]. Moreover, heat dissipation can change along the height of a work piece, leading to different layer heights on different work piece positions. With the correct welding parameters found, the manufacturing can be done layer by layer, and the torch can move a predefined step upward after each layer [7]. Even small deviations between the actual height step and the driven one can accumulate over the layers and lead to a deviating contact tube 
to working distances (CTWD). A too big CTWD can lead to improper shielding gas conditions and thereby a higher porosity [7]. A too small CTWD can lead to a higher spatter rate or even a collision between the torch and the work piece [7].

To avoid extensive preliminary studies, a closed-loop control of the welding process is necessary. For closed-loop control, knowledge of the actual bead height is needed to be able to raise the torch after the deposited layer by the required amount. The bead height can be determined by using external sensors such as a charge-coupled device camera (CCD) [7].

A system that detects the distance between the torch and work piece in GTAW is described by Wang et al. [8]. The system is reported to have an accuracy of around $1.5 \mathrm{~mm}$ in $z$-direction. The system works by using a linear relationship between the voltage, the current, and the arc length. Most of the errors are caused by the changes in the wire feed speed, and the system can only be used in GTAW-WAAM. [8]

Barborak et al. [9] have done a correlation analysis of different characteristic waveform features of the welding signal. The experiments were done in short circuiting as well as in spray transfer mode of GMAW. The authors measured a strong correlation between CTWD and the standard deviation of current, the mean current, as well as the mean short circuit time [9].

The electrode extension of GMAW during spray-transfer mode was analyzed by Bingul and Cook [10]. The authors defined the process voltage as a summation of the voltage drop over the electrode extension, the cathode, the arc, and the anode. Each voltage drop is then calculated. Therefore, the temperature-dependent heat content of the wire is calculated. The system could predict the electrode extension with an accuracy of $\pm 0.6 \mathrm{~mm}$ [10]. This method would allow, considering a stable arc length, the CTWD determination based on the voltage and current signal in GMAW spraytransfer mode.

An artificial neutral network (ANN) is used in [11] to detect the CTWD in GMAW. Specifically, the travel speed, thickness of specimen, feeding speed, wire electrode diameter, the current, and voltage filtered by a moving mean filter as well as the root mean square of the current and voltage are passed to the ANN. The ANN is reported to detect changes in the CTWD within $0.147 \mathrm{~s}$. A statement about the accuracy of the CTWD cannot be made, as the defuzzification step is missing. As the thickness of the specimen plays an important role during the evaluation, it is not clear, if this method is applicable for WAAM [11].
In [12] a control loop based on the layer height is established. This allows depositing an even surface on an uneven substrate. In this approach, the weld bead is measured by a digital light processing 3D scanner. Through the known distance to the work piece, the welding speed is modified between 4 and $8 \mathrm{~mm} / \mathrm{s}$. Slower welding speeds lead to higher beads, while higher speeds lead to lower beads. By modifying the speed, the authors are able to achieve the desired bead height. However, this also influences the bead width. The bead width is stated to range from 4.5 to $10 \mathrm{~mm}$, while the height only ranges from 1.5 to $3.1 \mathrm{~mm}$ [12].

Another attempt to overcome the problems resulting from the height step is shown by Xiong et al. [13]. The authors used a CCD camera and digital image processing to record the nozzle to top surface distance (NTSD) and bead width in GMAW. This system is then used for controlling the deposition rate. With controlled deposition rate, the NTSD can be controlled with an accuracy of $\pm 0.5 \mathrm{~mm}[7,13,14]$.

Reisgen et al. create a layer-wise elevation map of the previous deposited layer using optical image processing [15]. This is then used for implementing two control loops of the layer height. One controls the distance between the torch and the work piece, and the second controls the wire feed speed. The system reduces the deviation of the actual height to the target height from $25 \%$ in the uncontrolled case to $7 \%$ for the controlled system [15].

A triangulated light sensor is used in [16] to measure the work piece height. The travel speed is set accordingly to the acquired height of the underlying layer by using a fuzzy-logic controller. This control strategy was applied on a work piece with 15 layers and 4 beads per layer. A total height error of $0.14 \mathrm{~mm}$ was achieved. However, the use of the sensor required measurement cycles in which the sensor passes along the work piece, which leads to an enlarged total build time [16].

In [17] a layer height control system for a GTAW-WAAM manufacturing process is introduced. A camera measures the amount of deposited material and the current shape of the layer. The data is then used to adjust the wire feed speed according to a linear control strategy. This system allows a closed-loop WAAM process. The authors state that stable initial welding parameters still need to be chosen [17].

However, the use of external devices to measure the layer height step affects the shape and increases the size of the welding torch, and thus limits its flexibility. Hence, the present study focused on the evaluation of the electrical signal from the process in order to extract information of the height step. Different features of the welding signal were extracted 
during GMAW-based WAAM and tested for correlation with the CTWD to determine their suitability for process control.

\section{Materials and methods}

The experiments were conducted with an Abicor Binzel ROBO WH W 500 torch and a Carl Cloos GLC 303 PA/3 welding rectifier. The advantage of this rectifier is its internal constant voltage characteristic. By contrast, most modern power sources have digital control loops, which vary the current output during short circuit in order to limit the amount of heat input. This may disturb our measurements. The experimental setup is shown in Fig. 1.

The torch was moved upward and sideward using a CNC system with stepper motors. In the experiments, the initial CTWD was set to $5 \mathrm{~mm}$ and raised continuously during the movement of the torch up to a final CTWD of $30 \mathrm{~mm}$. The actual welding parameters are shown in Table 1 . The current was measured by a Chauvin Arnoux PAC22 clamp meter. The torch moving direction and electrical connections are shown in Fig. 2.
Table 1 Welding parameters

\begin{tabular}{ll}
\hline Welding speed & $0.3 \mathrm{~m} / \mathrm{min}$ \\
Initial CTWD & $5 \mathrm{~mm}$ \\
Target CTWD & $30 \mathrm{~mm}$ \\
Slope length & $70 \mathrm{~mm}$ \\
Process gas & ISO $14175 \mathrm{M} 21\left(\mathrm{Ar}-\mathrm{CO}_{2}\right.$ 82-18) \\
Process gas flow & $181 / \mathrm{min}$ \\
Substrate material & Mild steel (S235) \\
Wire material & EN ISO 14341-A (2011) G42 4M21 3Si1 \\
Wire diameter & $1.2 \mathrm{~mm}$ \\
Wire feed speed & $3.4 \mathrm{~m} / \mathrm{min}$ \\
Mean current & $170 \mathrm{~A}$ \\
Mean voltage & $14.5 \mathrm{~V}$ \\
\hline
\end{tabular}

The voltage was recorded between a connection port of the torch directly behind the torch neck and the work piece ground. A voltage divider with a division of 1:5 was used to make it compatible with the measurement range of the NI USB-6361 National Instruments A/D converter, and all signals were fed through coated BNC cables. The actual
Fig. 1 Experimental setup with power source, data acquisition platform, current measurement device, torch, work piece, and axis system

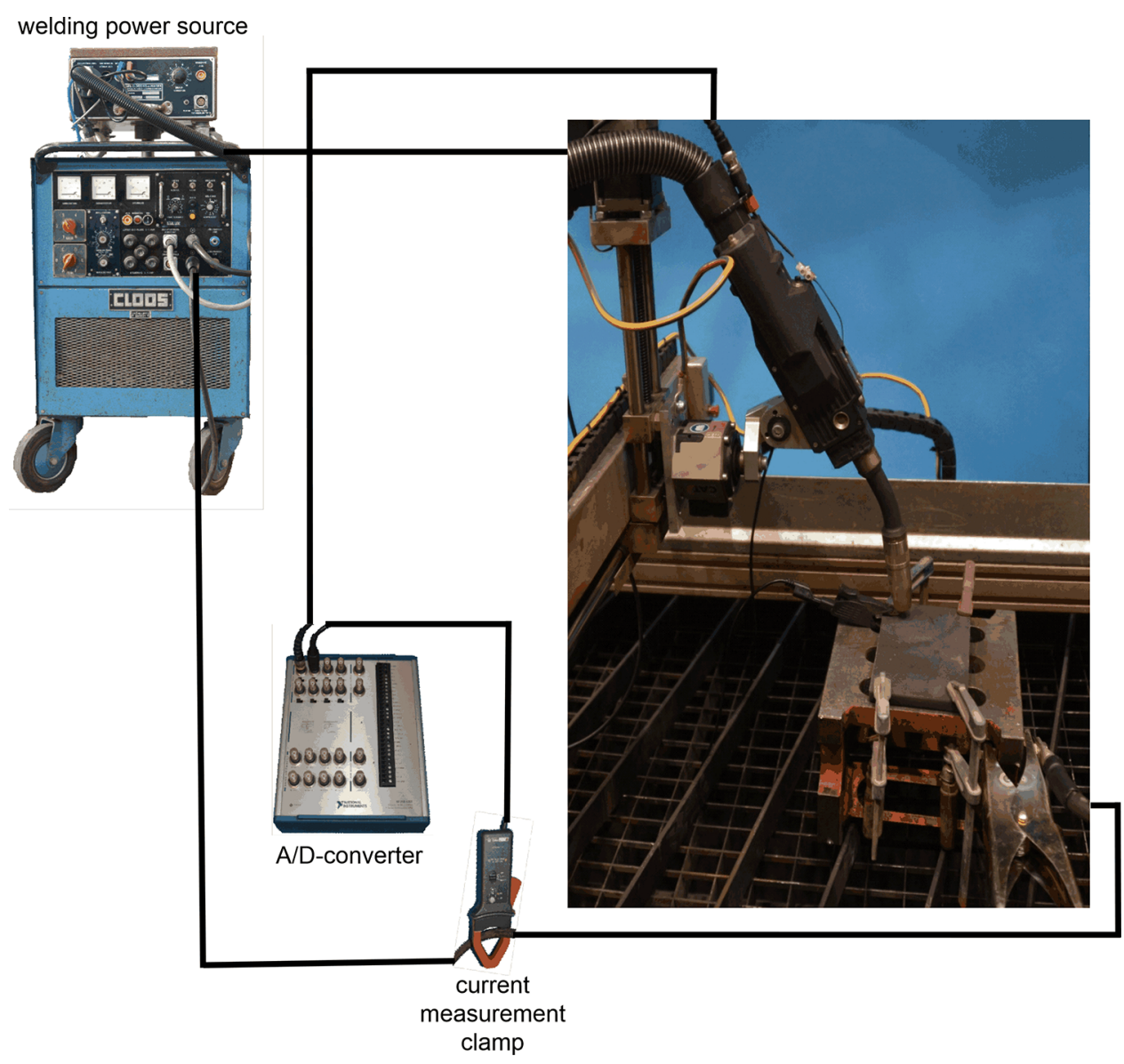


Fig. 2 Experimental setup with torch moving direction and electrical connections

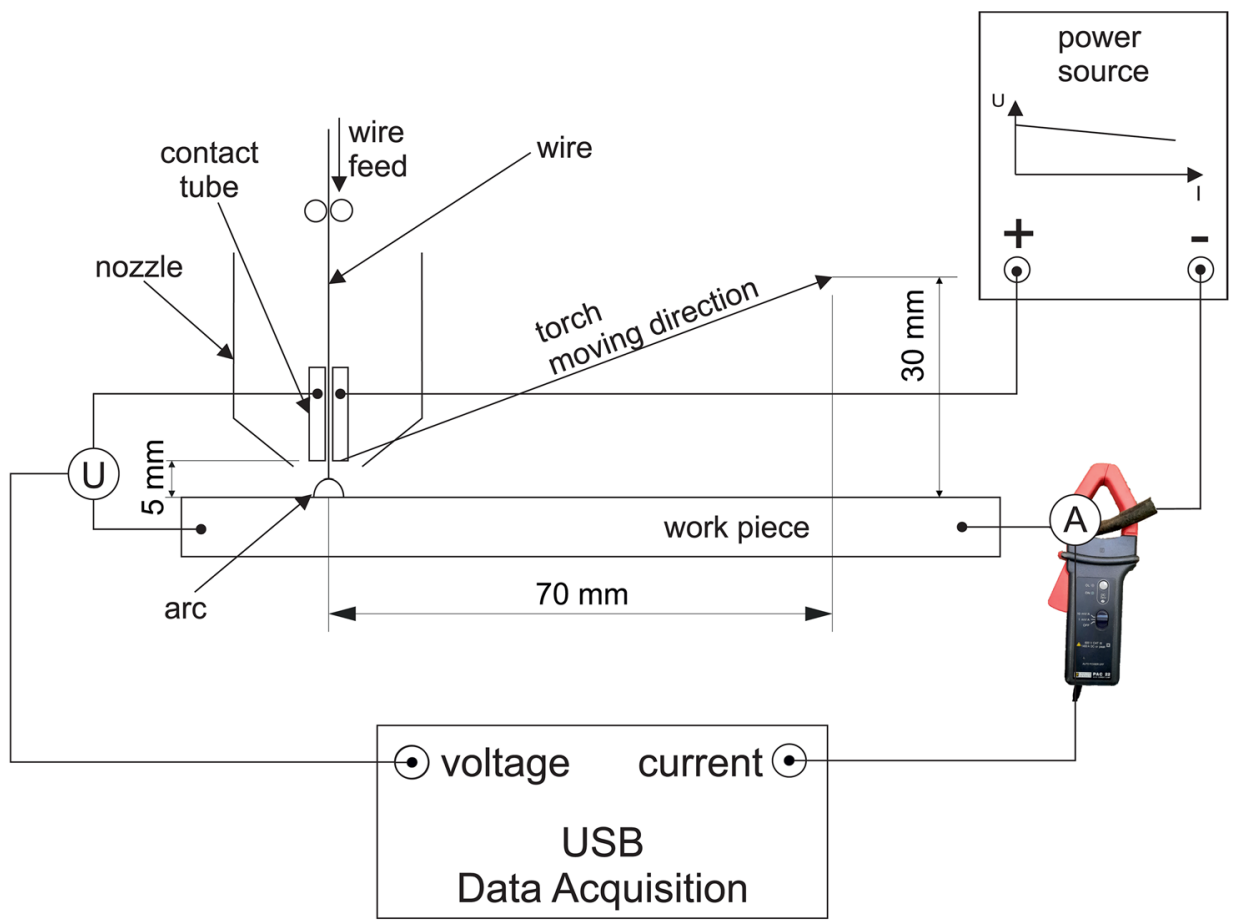

measurements were taken with 50.000 samples per second, and the acquired data is available in a data repository [18].

The recorded signal was processed to provide short circuit time and arc burning time. Arc existence was defined as the voltage being higher than the sum of the cathode and anode fall region. In [19] the sum of voltages over the anode and cathode for an $100 \%$ argon arc are estimated as $17.4 \mathrm{~V}$ and lower voltage indicates a short circuit. However, choosing $17.4 \mathrm{~V}$ as the threshold could provide false short circuit detections resulting from measurement fluctuations. The probability of the occurrence of a voltage value for the given set-up is shown in Fig. 3. To determinate a good threshold between arc existence and short circuit, the voltage value with the least occurrence between 0 and $17.4 \mathrm{~V}$ was chosen as the threshold voltage, which was $14 \mathrm{~V}$ in this case. In addition, to avoid false triggers for short circuit events, the voltage had to be below the threshold for at least $30 \mu \mathrm{s}$.
Theoretically, the arc welding process takes place in the Ohmic range with respect to the current flow through the arc column. The dynamic processes located in the Ohmic region of the arc characteristic can be described by linear functions, whereby the working point shift must be controlled by the welding machine's power supply (Fig. 4). The continuously changing arc conditions shift the operating point in an essentially similar cycle as shown schematically in Fig. 4 in its U/I dependence. Starting from point 1, i.e., the burnout of the short circuit bridge and the re-ignition of the arc, the operating point shifts abruptly to point 2 , the value of the maximum arc voltage. Subsequently, the arc shortens due to the feed motion of the wire and the formation of the melting droplet until point 3 is reached. Next, the process is again in short circuit and the arc is extinguished, which is characterized by the abrupt voltage drop and the shift to point 4 in the U/I diagram. The welding current source then supplies the
Fig. 3 Kernel-density distribution with short circuit criteria during welding with a wire feed speed of $3.4 \mathrm{~m} / \mathrm{min}$

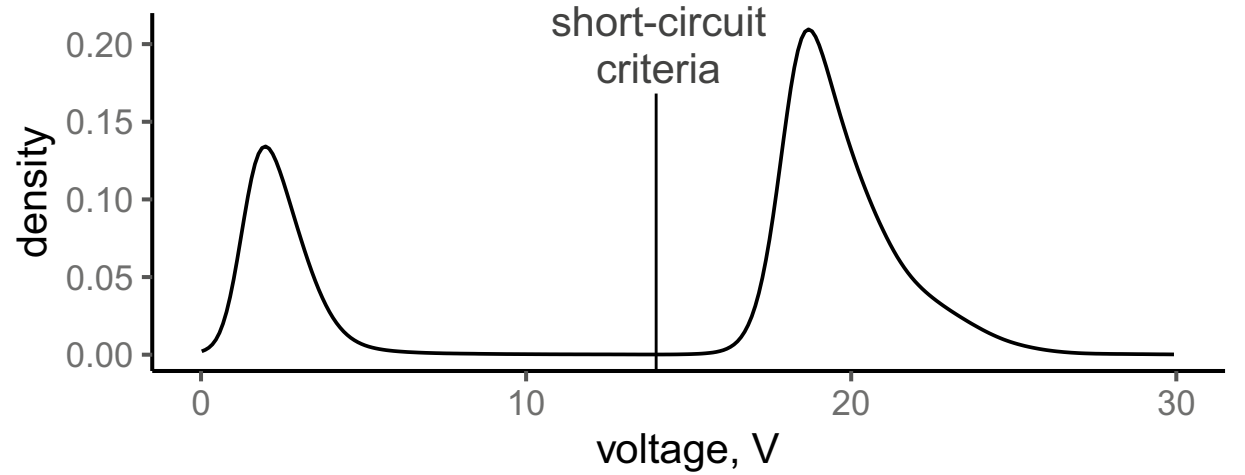


Fig. 4 Schematic drawing of the typical voltage and current history of GMAW in short circuit mode

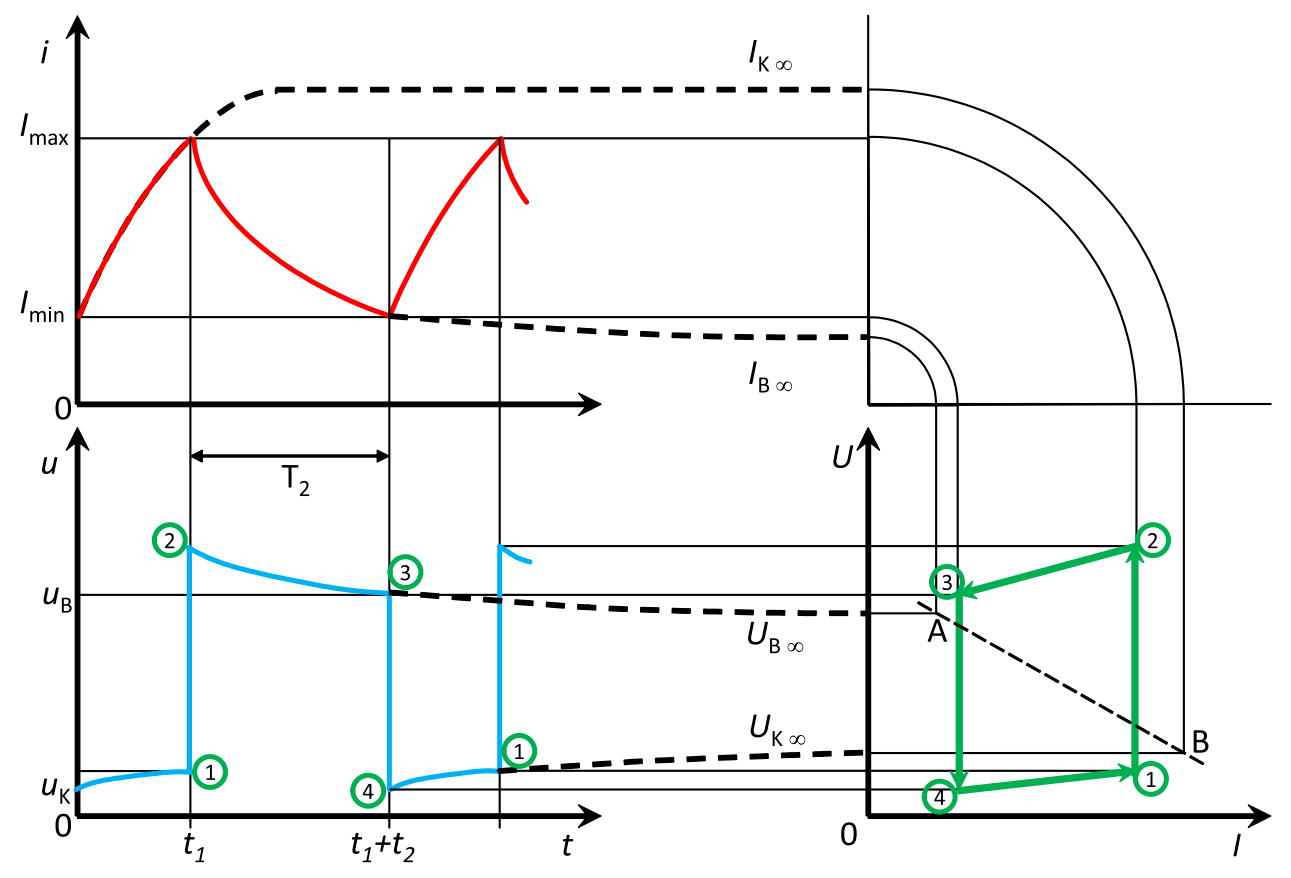

necessary energy to dissolve the short circuit bridge with a renewed shift of the process to point 1 . The shifts from 1 to 2 and 3 to 4 are abrupt because they are pure voltage changes, while for the shifts from 2 to 3 and 4 to 1 are characterized by the inductances and the associated current changes, and thus these require substantially more time [20].

The characteristic values that were extracted from the signal are the average voltage during the short circuit event, the minimal voltage during the short circuit event, and the duration of the short circuit event. The maximal voltage during short circuit was not captured since this by definition is the threshold value of $14 \mathrm{~V}$. The characteristic values extracted of the arc during the burning time were the maximum, minimum, and average voltages as well as the duration of the arc existence. Figure 5 shows an example of the signals recorded during a stabilized GMAW-S process.
Fig. 5 Characteristic voltage, current, and resistance trend with extracted values during a stabilized GMAW-S process; green color indicates the short circuits

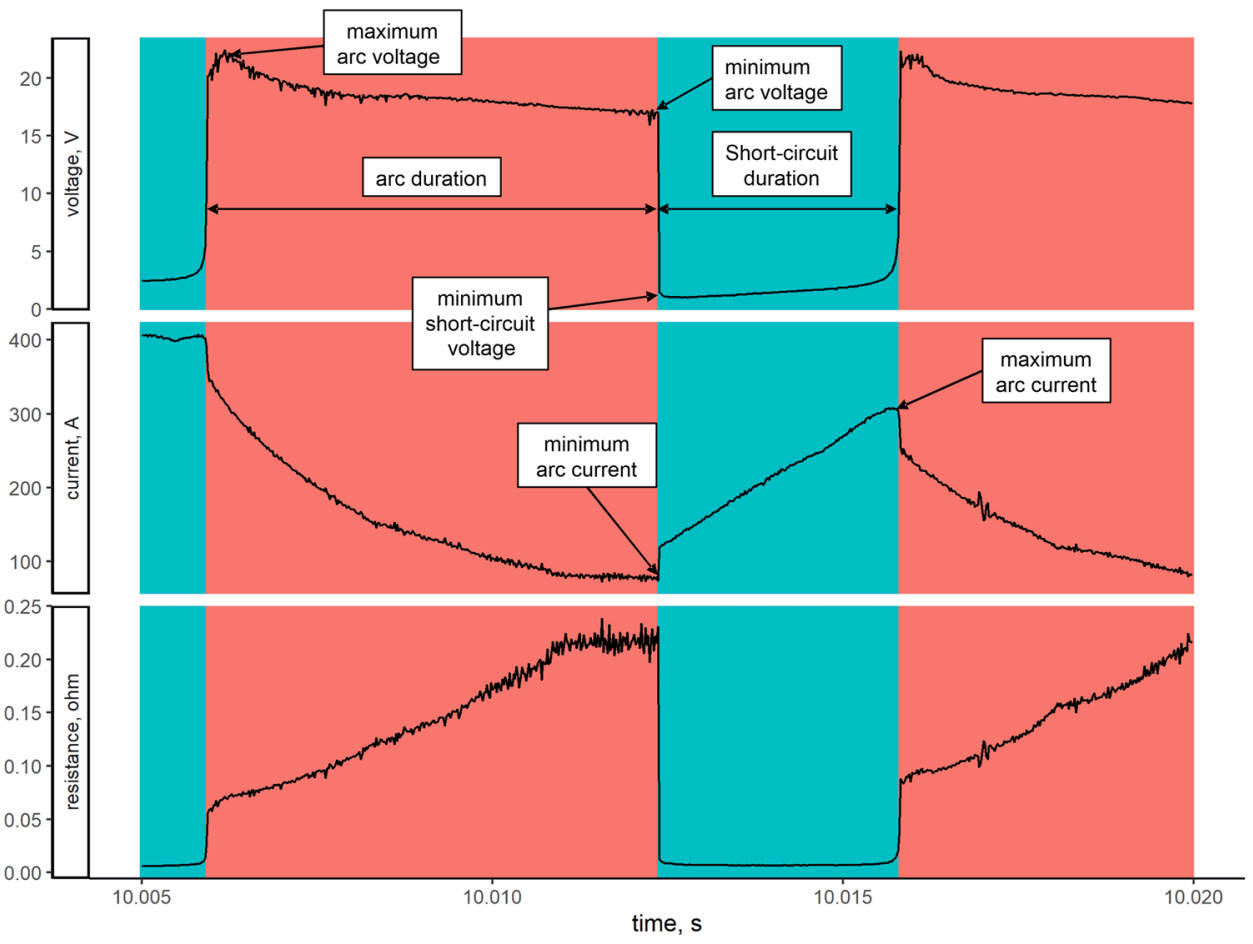


Table 2 Comparison of different characteristic values fitted to the CTWD during a short circuit

\begin{tabular}{lccc}
\hline Value & Average voltage & Minimal voltage & Average duration \\
\hline Linear regression gradient $(a)$ & $7.2 \mathrm{~mm} / \mathrm{V}$ & $12.2 \mathrm{~mm} / \mathrm{V}$ & $-11.7 \mathrm{~mm} / \mathrm{ms}$ \\
Offset $(b)$ & $-5.2 \mathrm{~mm}$ & $-3.0 \mathrm{~mm}$ & $21.0 \mathrm{~mm}$ \\
Correlation coefficient & 0.91 & 0.83 & -0.15 \\
\hline
\end{tabular}

The resistances during the arc burning phase and during the short circuit phase were also evaluated. The characteristic resistance trends during short circuit GMAW are shown in Fig. 5. During arc existence, the resistance rises continuously because the arc length decreases, while the electrode extension increases. During short circuit the arc extinguishes and is no longer part of the electric circuit [20].

To determine which characteristic value has the highest correlation with the CTWD, the correlation coefficient $r_{x y}$ was calculated for each value. Since the correlation coefficient is only showing the degree of linear dependence, the extracted characteristic values with the highest correlation were then fitted to a linear function of the CTWD using the method of least squares.

The features with the strongest measured correlations were then evaluated by comparing the actual CTWD to the calculated CTWD by welding with constant CTWD and by welding a ramp with a different slope and with different welding parameters, e.g., wire feed speed.

\section{Results and discussion}

The results showed a clear correlation between the average voltages during short circuit and the CTWD. At the beginning of the short circuit event, a droplet of the wire touches the melt pool [21]. This is the start of the droplet transfer from the melted electrode into the melt pool. During this period, the only resistance in the circuit is the wire, the drop at the wire tip, and the work piece [22]. These are very repeatable resistances and thereby lead to repeatable voltages. The resistance of the wire depends strongly on the diameter and material of the electrode. Moreover, the temperature of the wire also influences the resistivity [23]. Therefore, the average voltage during this drop transfer is closely related to the CTWD. The correlation between the minimal voltages and the CTWD appeared to be smaller.
The duration of the short circuit event showed the least correlation. As demonstrated in [21], bigger drops require a longer transfer time, so they result in longer short circuit durations. Since the CTWD and the short circuit duration are not correlated, it can be assumed that the CTWD does not influence the drop size or the drop transfer velocity. Characteristic values acquired during a short circuit are listed in Table 2.

None of the values collected during the arc burning time showed a good correlation with the CTWD. Since the arc length should always be similar after every re-ignition, the arc length is independent of the CTWD. The average voltage of the arc is more or less constant. Voltage deviations are only influenced by the electrode extension, which changes its length due to changes in CTWD. Maximal arc voltages occur shortly after the end of the short circuit during the re-ignition. Minimal arc voltages occur shortly before the arc extinguishes. Since the arc resistance decreases with decreasing arc length, the contribution of the wire resistance to the total resistance increases.

The arc duration is given by the end of the short circuit at which the wire loses the contact to the melt pool and the beginning of the next short circuit at which the wire touches the melt pool. The lack of correlation with the CTWD can be explained by deviations in electrode extension during the re-ignition. The correlation coefficients as well as the parameters for the linear fit functions are listed in Table 3.

All current-related values show medium correlation with the CTWD. The average arc current decreases during the experiment. When the torch moves upward, the arc length increases for a short moment. The constant voltage characteristic of GMAW power sources lowers the current, when the arc length increases. Since the melting rate is highly dependent on the current, the melting rate decreases as well [24]. Thereby, the arc length is stabilized to a constant value. However, in order to obtain this arc length, the current needs to decrease constantly.
Table 3 Comparison of different characteristic values fitted to the CTWD during arc existence

\begin{tabular}{lclcc}
\hline Value & Average voltage & Maximal voltage & Minimal voltage & Average duration \\
\hline Linear regression gradient $(a)$ & $3.2 \mathrm{~mm} / \mathrm{V}$ & $0.40 \mathrm{~mm} / \mathrm{V}$ & $0.10 \mathrm{~mm} / \mathrm{V}$ & $0.002 \mathrm{~mm} / \mathrm{V}$ \\
Offset $(b)$ & $-46.8 \mathrm{~mm}$ & $8.4 \mathrm{~mm}$ & $15.8 \mathrm{~mm}$ & $16.8 \mathrm{~mm}$ \\
Correlation coefficient & 0.34 & 0.11 & 0.01 & 0.04 \\
\hline
\end{tabular}


Table 4 Comparison of different characteristic current values fitted to the CTWD during arc burning time

\begin{tabular}{llccc}
\hline Value & Average arc current & Maximal current & Minimal arc current & Short circuit current \\
\hline Linear regression gradient $(a)$ & $-0.17 \mathrm{~mm} / \mathrm{A}$ & $0.18 \mathrm{~mm} / \mathrm{A}$ & $-0.18 \mathrm{~mm} / \mathrm{A}$ & $-0.10 \mathrm{~mm} / \mathrm{A}$ \\
Offset $(b)$ & $40.6 \mathrm{~mm}$ & $-68.9 \mathrm{~mm}$ & $32.8 \mathrm{~mm}$ & $36.3 \mathrm{~mm}$ \\
Correlation coefficient & -0.59 & 0.35 & -0.43 & -0.54 \\
\hline
\end{tabular}

Maximal current and minimal current show correlations in different directions. While the maximal current rises with increasing CTWD, the minimal current decreases with rising CTWD. The short circuit current decreases with increasing CTWD. All current-related values are listed in Table 4.

The resistance during the arc existence shows only medium correlation with the CTWD. This is because the arc always remains at a similar length. Only the electrode extension increases. Therefore, the resistance of the wire increases the total resistance.

During the short circuit event, the main resistance in the circuit is the electrode extension. When setting the CTWD to 0 , so that the contact tube touches the work piece, a resistance of $0.9 \mathrm{~m} \Omega$ was measured. This is less than the mean short circuit resistance of $129 \mathrm{~m} \Omega$ during the welding experiment. The data for the correlation between the CTWD and the resistances are summarized in Table 5. Additional effects to the resistances in the work piece were negligible in the present study. When the main resistance in the circuit is the electrode extension, one can calculate the CTWD based on Eq. (1). The short circuit resistance is obtained from the temperature-dependent specific resistivity, $\Psi(T)$, the cross-section, $A_{\text {wire }}$, and the extension of the wire, $L,[10]$ as

$R_{\mathrm{sc}}=\frac{U_{S C}}{I_{S C}}=\frac{\Psi(T)}{A_{\text {wire }}} * L$

During short circuit time, $L$ becomes equivalent to the CTWD, and the short circuit resistance shows a strong correlation with the CTWD. The specific resistivity $\Psi(T)$ is a material and temperature-dependent parameter. As wire

Table 5 Comparison of different resistances fitted to the CTWD

\begin{tabular}{lll}
\hline Value & Resistance arc & Short circuit resistance \\
\hline Linear regression gradient $(a)$ & $-0.17 \mathrm{~mm} / \Omega$ & $1131.3 \mathrm{~mm} / \Omega$ \\
Offset $(b)$ & $40.6 \mathrm{~mm}$ & $-2.6 \mathrm{~mm}$ \\
Correlation coefficient & -0.59 & 0.98 \\
\hline
\end{tabular}

diameter and material are constant throughout the process, the heating up of the wire is the only transient aspect.

In Fig. 6, the three values with the highest correlation are plotted against the CTWD. Each gathered value is shown in the plot. The dashed line shows the actual CTWD as it was defined in the CNC program during the short circuit event. The values are plotted against the number of the short circuit event, since measurement values can only be gathered during the process inherent short circuits. The standard deviation of the calculated CTWD values using the short circuit resistance is $\pm 1.2 \mathrm{~mm}$. The standard deviation in case of using the average short circuit voltage is $\pm 2.8 \mathrm{~mm}$, and for the minimal short circuit voltage case it is $\pm 3.8 \mathrm{~mm}$.

The best fit for calculating the CTWD based on the short circuit resistance data obtained was

$\mathrm{CTWD}=1131.3 \frac{\mathrm{mm}}{\Omega} * R_{\mathrm{sc}}-2.6 \mathrm{~mm}$

This indicates a resistivity of $110^{-6} \Omega \mathrm{m}$. According to Zhang et al. this is the resistivity of the given welding wire alloy at $1000 \mathrm{~K}$ [23].

This correlation was then evaluated further with three different sample weldings. The first sample tested the accuracy during welding on a flat surface, i.e., without a change in CTWD. To check the range of deviations, the second test is a repetition using the same slope as in the training test. To test, whether the method is also applicable with different wire feed speeds, a reduced wire feed speed of $2.5 \mathrm{~m} / \mathrm{min}$ and a reduced bead length of only $50 \mathrm{~mm}$ was used for the third case. The changed welding parameters are listed in Table 6. The calculated CTWDs of the three weld samples are shown in Fig. 7. The values measured for welding on the flat surface show a standard deviation of $\pm 1.4 \mathrm{~mm}$ with a mean value of the CTWD of $10.8 \mathrm{~mm}$. The closest fitting was achieved on the sample that was welded with the same parameters as the training sample. Here a standard deviation of $\pm 1.3 \mathrm{~mm}$ was obtained. The third test in which the sample was welded with a lower wire feed speed showed a small standard deviation of $\pm 1.0 \mathrm{~mm}$. 
Fig. 6 CTWD estimated based on three different features extracted out of the signal along the occurrence of measurement value; the dashed orange lines show the actual evolution of the CTWD as defined by the CNC program
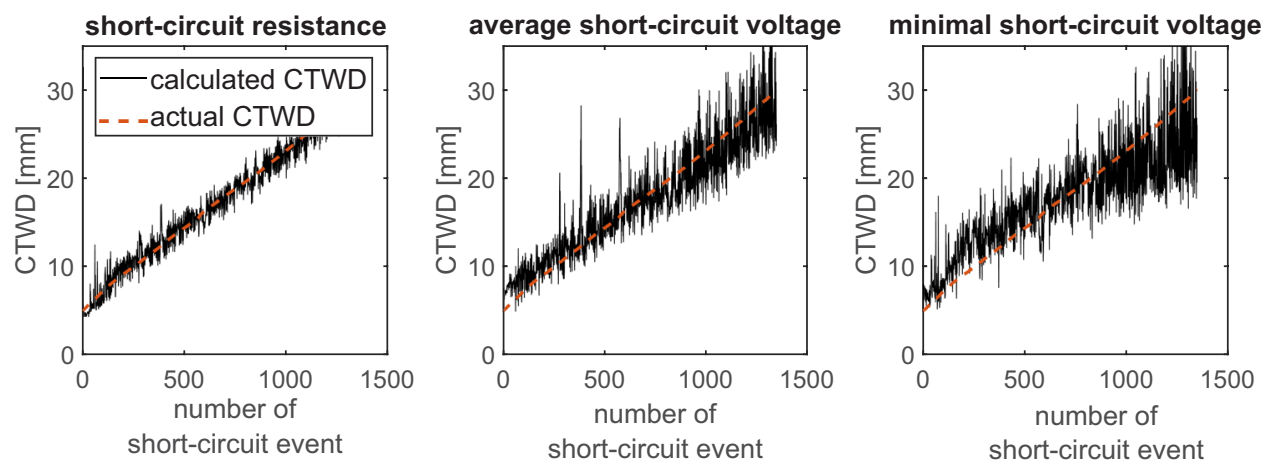

Table 6 Parameters for evaluation experiments (see main text for details)

\begin{tabular}{lll}
\hline Type of test & Wire feed speed & CTWD \\
\hline 1 & $3.4 \mathrm{~m} / \mathrm{min}$ & $10 \mathrm{~mm}$ \\
2 & $3.4 \mathrm{~m} / \mathrm{min}$ & 5 to $30 \mathrm{~mm}$ \\
3 & $2.5 \mathrm{~m} / \mathrm{min}$ & 5 to $30 \mathrm{~mm}$ \\
\hline
\end{tabular}

Due to the lower wire feed, the process was not able to restart after a short circuit event at a CTWD of $23 \mathrm{~mm}$. However, the calculated CTWD values had a constant offset toward higher values (Fig. 7). This could be caused by a lower wire temperature due to less Joule heating, which also lowers the specific resistivity [22, 23]. To overcome this issue and lower the error, the coefficients in Eq. (2) need to be recalibrated for each wire feed rate.

All samples together demonstrated a standard deviation of $\pm 1.6 \mathrm{~mm}$ for the CTWD. These standard deviations might seem large, but since the deviations have a Gaussian distribution, they can be lowered using a moving mean filter. Using a moving mean filter with a window of 10 short circuit events, a standard deviation of $\pm 1.18 \mathrm{~mm}$ could be realized. Standard deviations this low are sufficient to control the CTWD of the torch. This accuracy allows a constant build process and prevents collisions between torch and work piece.
WAAM often employs the energy-reduced welding process "cold metal transfer" (CMT), which deducts the wire from the work piece during short circuit. To prove that the short circuit resistance can also be used when manufacturing work pieces with CMT, the slope and the constant CTWD are welded again with a Fronius TransPuls Synergic 4000 CMT R welding power source with a CMT process, using with a KUKA KR 125/1 robot as traversing unit. The measured short circuit resistances are evaluated and processed using Eq. (2). The results are shown in Fig. 8. The gathered electrical measurements are available in [18].

Notably fewer short circuit events happen during CMT than during the standard short circuit welding. Equation (2) leads to a standard deviation of $\pm 1.4 \mathrm{~mm}$ when welding the slope. When welding with a constant CTWD, the standard deviation lowers to $\pm 0.4 \mathrm{~mm}$.

It has to be noted that Eq. (2) is only valid for the conditions used, i.e., a wire made out of mild steel with a diameter of
Fig. 7 Results of the calculated CTWD from the validation tests; the dashed orange lines show the actual evolution of the CTWD as defined by the CNC program
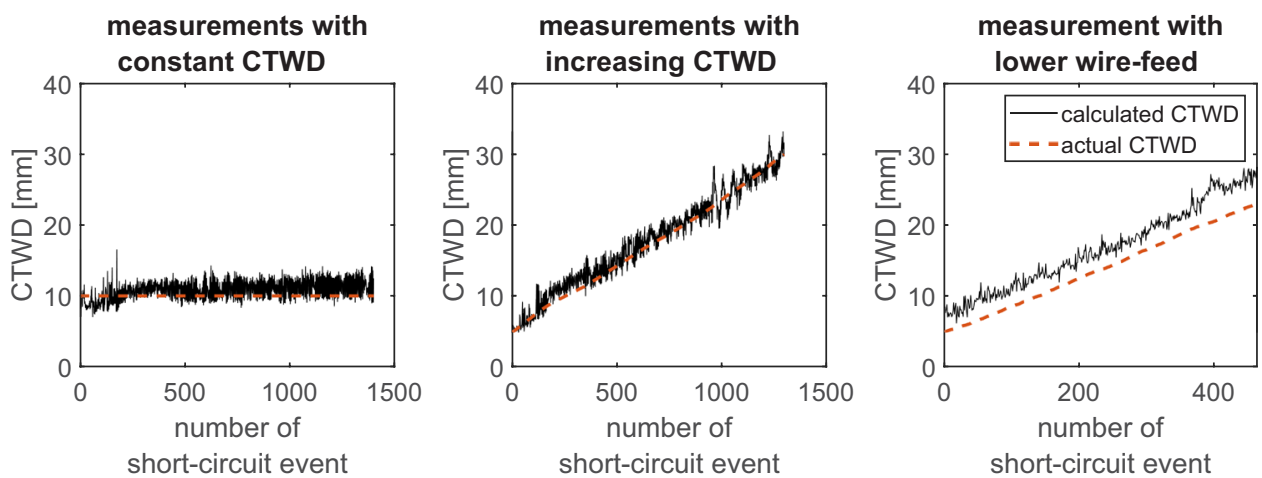
Fig. 8 Results of the calculated CTWD from experiments with CMT welding; the dashed orange lines show the actual evolution of the CTWD as defined by the robot program
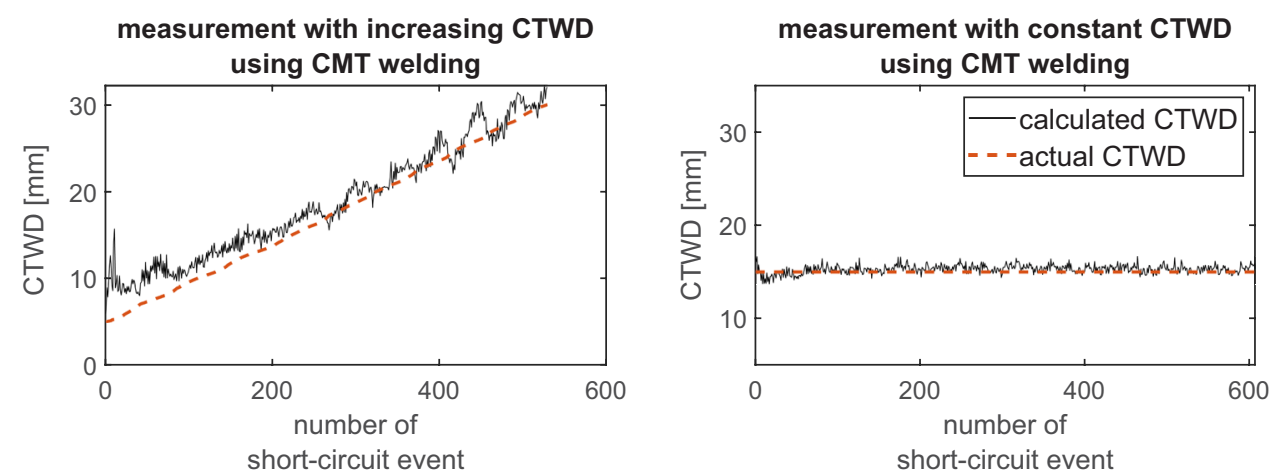

$1.2 \mathrm{~mm}$ in a GMAW-S or a CMT process. However, the found correlation allows a closed-loop WAAM process, where a controller keeps the short circuit resistance constant for any wire material. A change of the wire feed speed during the build-up would lead to different short circuit resistances and therefore needs an adaption of the controller setpoint.

\section{Possible sources of error}

The work of Ushio and Mao shows that electrode extension temperature is mainly influenced by Joule heating; only about $0.1 \mathrm{~mm}$ of the electrode is influenced significantly by heat conduction of the arc [22]. Since the on-passed wire remains at room temperature, the average wire temperature will remain constant even during longer welding times. On the other hand, Joule heating depends on electrode extension. Thus, a dependency of the regression coefficient in Eq. 2 and the electrode extension length might be possible. This is not a problem in a system with a constant CTWD, but it can lead to nonlinear regression in systems without. Furthermore, it implies that a different wire feed also leads to a different coefficient in Eq. (2).

Since the resistance of the contact tube is dependent on the current and variations in the raise of the current during the short circuit are possible, variations of the short circuit resistance based on the contact-tube resistance are possible [25]. The resistance of the work piece also influences the measurement values. To estimate the resistance, the contact tube was placed in direct contact with the work piece and after applying current a resistance of $0.9 \mathrm{~m} \Omega$ was measured. This resistance might change due to longer distances between the torch and the measuring clip. Therefore, the layer number needs to be considered when evaluating the signal.

Another reason for process variations is the drop instability before the wire touches the melt pool. The drop at the bottom of the electrode extension can occur in different sizes and shapes. This results in different cross sections through the drop and thereby different resistance values [26]. Since the measured resistance values show a Gaussian distribution, it can be assumed that the drop cross sections are Gaussian distributed.

Finally, the accuracy of the electrical measurement system can itself have a noticeable effect on the CTWD calculated. For the current setup, a mean short circuit current of $184 \mathrm{~A}$ and mean short circuit voltage of $3.1 \mathrm{~V}$ result in a standard deviation of $\pm 0.42 \mathrm{~m} \Omega$. With $1131.3 \mathrm{~mm} / \Omega$ in Eq. (2), this implies that the electrical measurement system influences the CTWD calculation with a standard deviation of $\pm 0.48 \mathrm{~mm}$.

\section{Summary}

WAAM can be done in a closed-loop process as shown in [7, 12, 13, 15-17]. However, the use of external sensors limits the freedom of build degrees. Acquiring height data coaxial with the wire can be done through the voltage and current signal.

To find out which feature of the voltage and current data can be useful, a correlation study was done. It was shown that the resistance during the short circuit is well suited for closed-loop process control. The resistance is dependent on the material, the wire temperature, and diameter as well as the CTWD. Since the fresh wire is fed continuously from the feedstock, it remains at near-constant temperature. The interpretation formula (Eq. (2)) allows determining the CTWD with an accuracy of $\pm 1.2 \mathrm{~mm}$. One key factor is the limited accuracy of the electrical measurement devices, which alone led to $\pm 0.48 \mathrm{~mm}$. This can be improved with more accurate current measurement devices. Still, the measurements are accurate enough to provide for sufficiently stable CTWD values during ramps and constant trajectories.

The method can be used for controlling the height step in GMAW-WAAM. Moreover, a system this accurate can be used to determine whether the torch passes over crossing weld beads or geometric irregularities existing in the $z$-direction. 
Author contribution $\mathrm{LVH}$ conducted the experiments and drafted the initial paper. TH and HJM conceived and led the project. HJM edited and revised the manuscript.

Funding Open Access funding enabled and organized by Projekt DEAL. The authors gratefully acknowledge funding of this project by the Ministry for Science and Culture of Lower Saxony (MWK) School for Additive Manufacturing SAM.

Availability of data and material Measured data available in [18].

\section{Declarations}

Ethics approval Not applicable.

Consent Not applicable.

Competing interests The authors declare no competing interests.

Open Access This article is licensed under a Creative Commons Attribution 4.0 International License, which permits use, sharing, adaptation, distribution and reproduction in any medium or format, as long as you give appropriate credit to the original author(s) and the source, provide a link to the Creative Commons licence, and indicate if changes were made. The images or other third party material in this article are included in the article's Creative Commons licence, unless indicated otherwise in a credit line to the material. If material is not included in the article's Creative Commons licence and your intended use is not permitted by statutory regulation or exceeds the permitted use, you will need to obtain permission directly from the copyright holder. To view a copy of this licence, visit http://creativecommons.org/licenses/by/4.0/.

\section{References}

1. Gorji NE, O'Connor R, Brabazon D (2021) XPS, SEM, AFM, and nano-indentation characterization for powder recycling within additive manufacturing process. IOP Conf Ser Mater Sci Eng 1182(1):12025. https://doi.org/10.1088/1757-899X/1182/1/012025

2. Rodrigues TA, Bairrão N, Farias FWC, Shamsolhodaei A, Shen J, Zhou N et al (2022) Steel-copper functionally graded material produced by twin-wire and arc additive manufacturing (T-WAAM). Mater Des 213:110270. https://doi.org/10.1016/j. matdes.2021.110270

3. Rodrigues TA, Duarte VR, Tomás D, Avila JA, Escobar JD, Rossinyol, E, Schell N, Santos TG, Oliveira JP (2020) In-situ strengthening of a high strength low alloy steel during wire and arc additive manufacturing (WAAM). Addit Manuf 34:101200. https://doi.org/10.1016/j.addma.2020.101200

4. Kazanas P, Deherkar P, Almeida P, Lockett H, Williams S (2012) Fabrication of geometrical features using wire and arc additive manufacture. Proc Inst Mech Eng Part B J Eng Manuf 226:10421051. https://doi.org/10.1177/0954405412437126

5. Ke WC, Oliveira JP, Cong BQ, Ao SS, Qi ZW, Peng B, Zeng Z (2022) Multi-layer deposition mechanism in ultra high-frequency pulsed wire arc additive manufacturing (WAAM) of NiTi shape memory alloys. Addit Manuf 50(1):102513. https://doi.org/10. 1016/j.addma.2021.102513

6. Rodrigues TA, Escobar JD, Shen J, Duarte VR, Ribamar GG, Avila JA et al (2021) Effect of heat treatments on 316 stainless steel parts fabricated by wire and arc additive manufacturing : microstructure and synchrotron X-ray diffraction analysis. Addit Manuf 48(46):102428. https://doi.org/10.1016/j.addma.2021.102428

7. Xiong J, Zhang G (2014) Adaptive control of deposited height in GMAW-based layer additive manufacturing. J Mater Process Technol 214:962-968. https://doi.org/10.1016/j.jmatprotec.2013.11.014

8. Wang X, Wang A, Li Y (2020) An online surface height measurement method for GTAW-based additive manufacturing, Weld. World 64:11-20. https://doi.org/10.1007/s40194-019-00813-1

9. Barborak D, Conrardy C, Madigan B, Paskell T (1999) Througharc process monitoring: techniques for control of automated gas metal arc welding. In Proceedings 1999 IEEE International Conference on Robotics and Automation (Cat. No.99CH36288C), Detroit, MI, USA, IEEE 10-15:3053-3058

10. Bingul Z, Cook GE (2006) A real-time prediction model of electrode extension for GMAW. IEEE/ASME Trans Mechatron 11:47-54. https://doi.org/10.1109/TMECH.2005.863366

11. Mahfudianto F, Warinsiriruk E, Joy-A-Ka S (2019) Estimation of contact tip to work distance (CTWD) using artificial neural network (ANN) in GMAW. MATEC Web Conf 269:4004. https:// doi.org/10.1051/matecconf/201926904004

12. Xu B, Tan X, Gu X, Ding D, Deng Y, Chen Z, Xu J (2019) Shapedriven control of layer height in robotic wire and arc additive manufacturing. RPJ 25:1637-1646. https://doi.org/10.1108/ RPJ-11-2018-0295

13. Xiong J, Yin Z, Zhang W (2016) Closed-loop control of variable layer width for thin-walled parts in wire and arc additive manufacturing. J Mater Process Technol 233:100-106. https://doi.org/ 10.1016/j.jmatprotec.2016.02.021

14. Xiong J, Zhang G (2013) Online measurement of bead geometry in GMAW-based additive manufacturing using passive vision. Meas Sci Technol 24:115103. https://doi.org/10.1088/0957-0233/ 24/11/115103

15. Reisgen U, Mann S, Oster L, Lozano P, Sharma R (2019) Study on workpiece and welding torch height control for polydirectional WAAM by means of image processing. IEEE Int Conf Autom Sci Eng (CASE) 6-11

16. Li Y, Li X, Zhang G, Horváth I, Han Q (2021) Interlayer closedloop control of forming geometries for wire and arc additive manufacturing based on fuzzy-logic inference. J Manuf Process. https://doi.org/10.1016/j.jmapro.2020.04.009

17. Muscato G, Spampinato G, Cantelli L (2008) A closed loop welding controller for a rapid manufacturing process. In 2008 IEEE International Conference on Emerging Technologies and Factory Automation, Hamburg, Germany, IEEE 1080-1083

18. Hölscher L, Maier HJ, Hassel T (2021) Dataset: CTWD slopes with GMAW. https://doi.org/10.25835/0011019

19. McIntosh C, Mendez PF (2017) Experimental measurements of fall voltages in gas metal arc welding. Weld J 96:121-132

20. Terasaki H, Simpson SW (2005) Modelling of the GMAW system in free flight and short circuiting transfer. Sci Technol Weld Join 10:120-124. https://doi.org/10.1179/174329305X29528

21. Bless SJ (1974) Drop transfer in short-circuit welding. J Phys D Appl Phys 7:526-539. https://doi.org/10.1088/0022-3727/7/4/306

22. Ushio M, Mao W (1996) Modelling of an arc sensor for DC MIG/ MAG welding in open arc mode: study of improvement of sensitivity and reliability of arc sensors in GMA welding (1st Report). Weld Int 10:622-631. https://doi.org/10.1080/09507119609549059

23. Zhang G, Goett G, Kozakov R, Uhrlandt D, Reisgen U, Willms K, Sharma R, Mann S, Lozano P (2019) Study of the wire resistance in gas metal arc welding. J Phys D Appl Phys 52:85201. https:// doi.org/10.1088/1361-6463/aaf5bb

24. Lesnewich A (1958) Control of melting rate and metal transfer in gas-shielded metal-arc welding. Weld J 37:Various pages

25. Shimizu H, Yokota Y, Mizuno M, Kurokawa T (2006) Wear mechanism in contact tube. Sci Technol Weld Join 11:94-105. https:// doi.org/10.1179/174329306X77885 
26. Tipi AD (2010) The study on the drop detachment for automatic pipeline GMAW system: short-circuit mode. Int J Adv Manuf Technol 50:149-161. https://doi.org/10.1007/s00170-010-2690-7
Publisher's note Springer Nature remains neutral with regard to jurisdictional claims in published maps and institutional affiliations. 